\title{
Historia del juego como ocio y las artes
}

\section{The History of Play as Leisure and the Arts}

Artículo recibido el II de febrero de 20I8; devuelto para revisión el I de agosto de 20I8; aceptado el Io de octubre de 20I8, http://dx.doi.org/I0.2220I/iie.I8703062e.20I9.II4.2664.

Rafael García-Sánchez Escuela Técnica Superior de Arquitectura y Edificación-Universidad Politécnica de Cartagena, España, rafael@sgbarquitectos.es, rafael.garcia@upct.es

Líneas de investigación Estética; historia de la arquitectura e historia del arte.

Lines of research Aesthetics; history of architecture and art history.

Publicaciones más relevantes Meditación sobre la ciudad actual (Murcia: Edit.um, 2013); El Renacimiento como artificio. Una aproximación cultural y estética (Madrid: Munilla-Leria, 2017); y Architectura et societas (Cartagena: CRAI, 2OI7).

Resumen El texto explora la dimensión retórica del juego y del arte. Retórica que no ha de entenderse como subsidiaria de la lógica y la gramática sino como la manera activa de perfeccionarlas. Ese perfeccionamiento puede realizarse en cualquier ámbito y momento de la vida cotidiana si es materializado genialmente. Se insistirá en que no es en la repetición y sujeción pasiva a reglas donde quepa esperar una comprensión, sino que es en el uso y en la actividad libres donde cabe la invención de lo inédito.

Palabras clave Arte; juego; praxis; ocio; Gadamer; retórica; belleza.

Abstract This text explores the rhetorical dimension of play and art. "Rhetoric" is understood not as a subordinate of logic and grammar but as the active way to perfect them. Such perfection can be sought out in any aspect and moment of daily life when inspired by genius. The article suggests that it is not in repetition and the passive subjection to rules that an understanding of the phenomenon is to be found, but rather in freedom and activity, which make possible the invention of the unprecedented.

Keywords Art; play; leisure; Gadamer; rhetoric; praxis; beauty. 


\author{
RAFAEL GARCÍA-SÁNCHEZ \\ ESCUELA TÉCNICA SUPERIOR DE ARQUITECTURA \\ Y EDIFICACIÓN-UNIVERSIDAD POLITÉCNICA DE CARTAGENA \\ ESPAÑA
}

\title{
Historia del juego como ocio $y$ las artes
}

"El hombre sólo juega cuando es hombre en el pleno sentido de la palabra, y sólo es enteramente hombre cuando juega."

"El juego es una función elemental de la vida humana, hasta el punto de que no se puede pensar en absoluto en la cultura humana sin un componente lúdico.” ${ }^{2}$

\section{Antecedentes}

P

or juego puede entenderse el conjunto de las actividades que el hombre libre, despreocupado de las obligaciones y premuras materiales, lleva a cabo en el ámbito del tiempo y el espacio lúdicos. Puede considerarse como lo alternativo o lo sucesivo al trabajo y al cabo, a lo que requiere esfuerzo; también como lo contrario y opuesto a la vida cotidiana de la gente corriente que es la que se halla atravesada por la necesidad y que caracteriza al mundo de los medios y de la instrumentalización.

I. Friedrich Schiller, Cartas sobre la educación estética del hombre (Barcelona: Anthropos, I990), 24I.

2. Hans-Georg Gadamer, La actualidad de lo bello (Barcelona, Buenos Aires y México: Paidós/ ICE-UAB, I99I), 66. 
Las actividades lúdicas se han venido considerando como libres, inútiles y desinteresadas al no estar determinadas por un fin utilitario extrínseco. Las útiles, en cambio, son las actividades serias. Serio es lo que tiene un fin más allá de sí mismo, estando vinculado al trabajo, al esfuerzo, a lo manual y a la remuneración económica. Más aún, lo serio es lo orientado a la producción y al "uso", dirá Platón, ${ }^{3}$ por eso la esencia de la seriedad productiva es correlativa al "desprendimiento de la obra respecto de su propio hacer" ${ }^{4}$ Lúdico y artístico, en cambio, no es lo que se ha concluido tras la ejecución de un trabajo, 5 no es propiamente un objeto, es lo que tiene un fin en sí mismo, y está vinculado con lo intelectual. Como ha recordado Larry Shiner, en la Antigüedad griega y romana "en general se mantenía un profundo prejuicio aristocrático contra el trabajo manual, sobre todo si era realizado por dinero, por muy inteligente, habilidoso o inspirado que fuese". ${ }^{6}$ Es sabido que en el mundo antiguo las élites culturales e intelectuales no escondían su más absoluto desprecio por quienes se ganaban la vida artesanalmente. Sócrates afirmaba que el trabajo manual deformaba el cuerpo y privaba de la amistad y la vida cívica.

Tienes razón, Critobulo, pues los llamados oficios manuales están desacreditados y, lógicamente tienen muy mala fama en nuestras ciudades, ya que dañan el cuerpo de los trabajadores y oficiales, obligándoles a permanecer sentados y a pasar todo el día a la sombra, y alguno de ellos incluso a estar junto al fuego. $Y$ al afeminarse los cuerpos se debilitan también los espíritus. Los oficios llamados manuales, sobre todo, no dejan tiempo libre para ocuparse de los amigos y de la ciudad de modo que tales obreros tienen mala fama en el trato con sus amigos y como defensores de la patria. Incluso en algunas ciudades, especialmente en las que tienen fama de belicosas, no se permite a ningún ciudadano ejercer oficios manuales. ${ }^{7}$

Tres siglos más tarde, Cicerón calificará de sórdido y vil, entre otros, el trabajo artesanal, viendo en su remuneración económica una forma de esclavitud, no en vano, sentencia en De officis que

3. "A qué tienden las propiedades, la belleza, la perfección de un mueble, de un animal, de una acción cualquiera, sino al uso a que cada cosa está destinada por su naturaleza o por la intuición de los hombres?", Platón, La República, X (México: Espasa Calpe, 1958), 6oId-e, 304.

4. Gadamer, La actualidad de lo bello, 47.

5. Hans-Georg Gadamer, Hermenéutica, estética e historia (Salamanca: Ediciones Sígueme, 20I3), 24I.

6. Larry Shiner, La invención del arte. Una historia cultural (Barcelona: Paidós Estética, 20I4), $5 \mathrm{I}$.

7. Jenofonte, Económico (Madrid: Gredos, 1993), 227. 
Llegados a este punto, en cuanto a qué profesiones son nobles y cuáles viles entre las manuales y las lucrativas, esto es aproximadamente lo que he entendido. [...] Son innobles y viles todos los trabajadores a sueldo que venden su esfuerzo, no sus habilidades, pues en ellos el salario mismo es el importe de su esclavitud. [...] Los artesanos se dedican todos a tareas viles, pues un taller no puede contener nada liberal. Y no hay que aprobar las tareas que están al servicio del placer, "pescaderos, carniceros, cocineros, polleros, pescadores", como dice Terencio. ${ }^{8}$

Ciertamente, estas devaluadas consideraciones sobre el trabajo manual dieron lugar a la clásica distinción entre artes serviles y liberales, cuya influencia se hará notar en todo el arco medieval, desde el siglo v al siglo XIV, tanto en la filosofía moral y la organización social, 9 como en la estética. ${ }^{\text {IO }}$ Tomás de Aquino se refirió a la división entre praxis y poiesis en la Summa Theologiae, I, I4,I6, en De Veritate, III,3, y en el Comentario a la Ética de Aristóteles, I, I,I3. En esta última obra señala la existencia de dos tipos de operaciones: las que son acción, esto es operantes, y las que son producción por trascender a la materia exterior.

En todo caso y con independencia del grado de nobleza o vileza del sujeto que las realiza, la división de las artes pone de relieve, entre otras cosas, la existencia de una distancia a recorrer, creando una nueva subdivisión: el hacer serio frente al hacer lúdico. Serio es lo propio del movimiento, de la distancia y del negocio. En cambio, lúdico es lo propio del reposo y del ocio, pues el fin se ha conquistado, estando en él como en un eterno presente que no tiene futuro ni pasado, un tiempo "indestructible", anota Eliade. ${ }^{\text {II }}$

En este sentido, las artes serviles, las del "reino de la necesidad" 12 nacen de la distancia, guardan relación con el tener que ir hacia aquello que se necesi-

8. Marco Tulio Cicerón, De oficiis. Quel che é giusto fare (Turín: Giulio Einaudi Editore, 20I2), cap. XLII, I5O, I24-I26.

9. Tal diferenciación fue visible en el humanismo aristocrático de la Antigüedad y en el humanismo estamental del medioevo. En ellos, se mantendrá con vigor la diferenciación de operaciones, y así será hasta el desarrollo urbano que tendrá lugar en la baja Edad Media y que encontrará su máximo esplendor en el humanismo renacentista donde comenzará a articularse una forma de unión entre praxis y poiesis, y al cabo entre ética, política, economía y artes.

ıo. Mariateresa Fumagalli, La estética medieval (Madrid: Antonio Machado Libros, 20I2), II5.

II. Mircea Eliade, Lo sagrado y lo profano (Barcelona: Paidós Orientalia, 2005), 67.

I2. Las expresiones "reino de la libertad" y "reino de la necesidad" las tomo prestadas de María Cristina Ríos, "El juego del arte como liberación”, Konvergencias Literatura, ańo III, núm. 7 (abril de 2008): 22-37. 
ta o que es la plenitud o fin aún no poseído y que da lugar al movimiento, ${ }^{13} \mathrm{al}$ trabajo y al esfuerzo, por tanto, a lo contrario del placer o la felicidad auténticos. Lo servil y vulgar es correlativo al reino de la necesidad y la carencia, a la falta de, al todavía no, por eso el futuro es el lugar al que llegar trabajosamente. Gadamer insiste en esta cuestión a propósito del estado del movimiento del ser en Aristóteles: "Mientras se halla en curso, no está perfeccionado. Lo que es movido está todavía en camino; no ha llegado aún. Está todavía en devenir." ${ }^{14}$ Las artes liberales, en cambio, y que a nuestro juicio guardan relación con la noción clásica de juego, nacen de la ausencia de "distancia", ${ }^{15}$ esto es, de necesidad; son las propias del "reino de la libertad" porque ya se ha llegado al fin, poseído como un presente pleno, no distanciado del futuro, un "presente siendo", que al estar en el fin ni se desgasta ni genera movimiento. ${ }^{16}$ El juego se asocia a las artes liberales porque, como le sucede a éstas, no está determinado por el para qué, tal es la proximidad existente entre lo teorético y lo estético. ${ }^{17}$ Lo liberal y lo lúdico, señala Tomás de Aquino "no se ordena a ningún fin extrínseco, sino que más bien se ordena al bien del que juega”. ${ }^{18}$

El divertimento lúdico no es propiamente una actividad en orden a un fin futuro sino que es lo que acontece en un presente absoluto "es una acción que tiene un fin en sí misma", ${ }^{19}$ "sin pasado ni porvenir, abstraído de la presión y de las coerciones del mundo", dirá Karl Gross, ${ }^{20}$ pleno, colmado de sentido: ${ }^{21}$ "el juego no tiene más sentido que el juego mismo", 22 "la finalidad del juego es el juego mismo", ${ }^{23}$ anota Caillois.

Así pues, lo servil y lo liberal, ${ }^{24}$ el reino de la necesidad y el de la libertad, lo trabajoso y lo lúdico, también lo ordinario y lo extraordinario, lo popular y lo

13. Ricardo Yepes, La región de lo lúdico. Reflexión sobre el fin y la forma del juego, Serie Universitaria, 30 (Pamplona: Cuadernos de Anuario Filosófico, 1996), 17.

I4. Gadamer, Hermenéutica, estética e historia, 236.

I5. Yepes, La región de lo lúdico. Reflexión sobre el fin y la forma del juego, 38.

16. Yepes, La región de lo lúdico. Reflexión sobre el fin y la forma del juego, 38.

17. Gadamer, Hermenéutica, estética e historia, 228.

I8. Tomás de Aquino, Suma teológica (Madrid: BAC, 2009), I-II, q. I, a.6.

19. Johan Huizinga, Homo ludens (Madrid: Alianza Editorial, 2007), 45.

20. Roger Caillois, Los juegos y los hombres. La máscara y el vértigo (México: Fondo de Cultura Económica, 1986), 269.

2I. Ríos, "El juego del arte como liberación", 25.

22. Caillois, Los juegos y los hombres. La máscara y el vértigo, 33.

23. Caillois, Los juegos y los hombres. La máscara y el vértigo, 276.

24. Wladyslaw Tatarkiewicz, Historia de seis ideas. Arte, belleza, forma, creatividad, mímesis, experiencia estética (Madrid: Tecnos/Alianza, 2004), 39-43 y 79-86. 
elitista, lo profano y lo sagrado ${ }^{25}$ se revelarán como realidades inconmensurables y heterogéneas, indiscernibles unas respecto de otras. "No son dos aspectos de un mismo orden fáctico", dirá Durkheim. ${ }^{26}$ Son realidades tan ontológicamente distintas, de naturaleza tan diversa, tal es la escisión y el conflicto existente entre ellas, que su reconciliación se volverá muy conflictiva, exigiéndose para estar en uno de esos reinos la desaparición completa del otro, cuya conexión sólo podrá materializarse por medio de convenidos ritos de paso.

Las personas cuya vida está vinculada al esfuerzo, lo trabajoso y lo propiamente mundano, al tiempo vacío y medible, ${ }^{27}$ sólo podrán acceder al espacio de lo lúdico, lo ligero de peso y lo artístico en sentido liberal, en un momento segundo dentro de la secuencia trabajo-descanso-trabajo, es decir, tras cumplir las obligaciones de la vida corriente, como si de un lujo o una fuga mundi se tratase. Allí se repondrán las fuerzas desgastadas por las tensiones de la vida cotidiana que, incomprensibles para el sujeto, lo deforman, ${ }^{28}$ alienándolo respecto de la realidad ordinaria e incluso de sí mismo. El arte y el juego sólo serían, parafraseando a Bayer, ${ }^{29}$ "el domingo de la humanidad".

\section{El juego y las artes liberales como praxis}

Ciertamente la distinción entre lo lúdico y lo serio, entre lo imponderable y lo medible, está emparentada con la dicotomía praxis (acción)-poiesis (producción) y que reseñara Aristóteles en su obra filosófica con la tensión entre la inutilidad y utilidad ${ }^{30}$ y con la distinción clásica entre ocio y negocio. Al respecto, es bien revelador el siguiente texto del estagirita en Metafisica

25. Eliade, Lo sagrado y lo profano.

26. Emile Durkheim, Las formas elementales de la vida religiosa. El sistema totémico en Australia (Madrid: Akal, 1982), 34 .

27. Es bien reveladora la distinción que Gadamer establece entre el "tiempo vacío" y el "tiempo pleno". El primero es medible y es el propio de un trabajo para un fin. El segundo, el de un acontecer que acontece, no se puede medir porque ni dura ni pasa, es el propio de la fiesta, la celebración, el juego y lo sagrado. Gadamer, Hermenéutica, estética e historia, 244.

28. Richard Shusterman, Pragmatist Asthetics. Living Beauty, Rethinking Art (Lanham: Rowman \& Littlefield Publishers, 2000), I68.

29. Raymond Bayer, Historia de la estética (México: Fondo de Cultura Económica, 1980), 314.

30. Nuccio Ordine, La utilidad de lo inútil (Barcelona: Acantilado, 2013). 
$\mathrm{Al}$ principio era natural que aquel que hubiera descubierto cualquier arte que trascendiera los simples conocimientos sensibles fuera objeto de admiración de los hombres, no sólo por la utilidad de su descubrimiento, sino porque se le creía sabio y superior al resto; pero posteriormente, cuando se descubrieron más artes y unas se aplicaron a necesidades y otras a pasatiempos, siempre fueron considerados más sabios los inventores de las segundas precisamente porque sus conocimientos no se destinaban a cubrir necesidades. A raíz de la consolidación de todas estas artes se inventaron las ciencias cuyo objeto no es ni el placer ni la utilidad, las cuales aparecieron primero en aquellos lugares donde existía el ocio; por eso las artes matemáticas nacieron en Egipto, puesto que allí la casta sacerdotal podía disfrutar de tiempo libre. ${ }^{31}$

La poiesis puede definirse como el conjunto de acciones cuya perfección se mide por la perfección de lo producido y cuyo fin es extrínseco. La forman las actividades que son un medio, son ponderables y cuantificables y, por tanto, tienen el carácter de instrumentales; su fin no es simultáneo a su realización. Son las actividades productoras o carentes de fin en sí mismas. Gadamer es bien ilustrativo al respecto, y califica a las actividades consideradas poiéticas de sustituibles, reemplazables y repetibles por lo que no pueden adquirir el estatuto ontológico de obras de arte, ${ }^{32}$ puesto que estas últimas son para sí mismas y se caracterizan por su libertad respecto de fines prácticos.

En contraste con la poiesis, la praxis es el conjunto de acciones que son fin en sí mismas, no tienen el carácter de medio ni se pueden instrumentalizar; en la praxis el fin es correlativo a la realización, su sentido no recae del lado de lo material, es más que un hacer artesanal, pues no produce nada útil ni tiene meta extrínseca alguna y sólo puede existir como sucede en el arte poético en "el ligero soplo del lenguaje y en el milagro de la memoria". ${ }^{33}$ Las acciones práxicas, son, a decir de Gadamer, las propias de las obras de arte por su representatividad, su irreemplazabilidad, pero sobre todo porque no son para un uso ni sirven como medio ni como instrumento ${ }^{34}$ pues, "poseen en su ejecución su ser perfecto". ${ }^{35}$

El juego recaería en el ámbito de la praxis dado que su finalidad es propiamente la de jugar y que el filósofo de Marburgo define como "el automovimiento que no tiende a un final o una meta, sino al movimiento en cuanto

3I. Aristóteles, Metafísica (Madrid: Alianza, 20I4), I (A), I, 98Ib, 44-45.

32. Gadamer, La actualidad de lo bello, 92.

33. Gadamer, Hermenéutica, estética e historia, 226.

34. Gadamer, La actualidad de lo bello, 92.

35. Gadamer, Hermenéutica, estética e historia, 240. 
movimiento". ${ }^{36} \mathrm{Al}$ seguir a Aristóteles, esta diferenciación permitiría distinguir a los hombres libres de los esclavos, a los que llevan en sí mismos el impulso de su movimiento de aquellos que lo poseen subordinadamente. Los primeros, "los que tienen en sí mismos, y no en otro su razón de existir" ${ }^{37}$ son los que realizan acciones emancipadas de la necesidad y los que realizan acciones en las que el agente progresa hacia sí mismo. Los segundos llevan a cabo actividades dependientes y meramente útiles, a saber, las que son un medio para un fin y que no perfeccionan a su agente ni le conducen a la virtud: "La vida es acción, no producción. Por ello el esclavo es un subordinado para las cosas prácticas." ${ }^{8}$

La distinción entre las artes liberales y las artes serviles se nutre de esta diferenciación antropológica: "Las artes vulgares son las que hacían intervenir el trabajo físico y el pago, mientras que las artes libres eran las intelectuales, apropiadas para las personas de alcurnia y cultivadas." 39 Las artes liberales, como la poesía y la música, son específicas de los hombres libres, los que llevan a cabo acciones práxicas, las propias del automovimiento e impulso libre, más nobles y exclusivas del ocio. ${ }^{40}$ Las artes serviles son eso, siervas, sórdidas y esclavas, porque están sujetas al dictado y a la norma extrínseca en vista de la cual se actúa, y son todas las artes relacionadas con la necesidad, desde la agricultura, la pesca, la herrería, la cerámica, las artesanías en su conjunto, también la pintura, la escultura y la arquitectura, y son las propias del neg-ocio $(a-s c h o l i ́ a){ }^{4 \mathrm{I}} \mathrm{y}$ de todo lo que conlleva un esfuerzo consciente. ${ }^{42} \mathrm{Al}$ respecto, Ordine recuerda, refiriéndose al Teeteto de Platón, que: "Los 'hombres libres' no tienen pro-

36. Gadamer, La actualidad de lo bello, 67.

37. Aristóteles, Metafísica, I(A), 2, 982b, 48.

38. Aristóteles, Politica (Madrid: Alianza, 2009), I, 5, I254a, 5 I.

39. Shiner, La invención del arte. Una historia cultural, 49.

40. Mary Beard ha advertido que la noción de ocio latina, otium, no debe entenderse como el periodo de tiempo en el que no hay nada que hacer sino más bien del tiempo del que somos auténticamente dueños. En este sentido el neg-ocio, negotium, debe comprenderse como ese tiempo cuyo dueño es otro, pero no uno mismo. El ocio sería lo propio del señorío y el negocio lo propio de la servidumbre. Mary Beard, SPQR. Una historia de la antigua Roma (Barcelona: Crítica, 20I6), 47I.

4I. En la cultura griega lo contrario de scholê (actividad noble con fin en sí misma) era su negación, $a$-scholía, esto es, el trabajo.

42. Al respecto, es bien revelador que la arquitectura, la pintura y la escultura no contaran con divinidades ni con musas. En cambio las artes de la palabra, las asociadas al lenguaje como las artes liberales que no son propiamente trabajo ni están remuneradas se llevan a cabo en el ocio y disfrutaban del patrocinio de sus musas. Walter F. Otto, Las musas y el origen divino del canto y del habla (Madrid: Siruela, 2005). 
blemas de tiempo y no han de rendir cuentas a nadie, mientras que los esclavos están condicionados por la clepsidra y por un amo que decide."43

\section{El juego como intermezzo reparador}

Las artes serviles y las acciones poieticas son consideradas como transeúntes por cuanto el fin no se halla en la acción, sino fuera de ellas y se mide, como se ha dicho, por la perfección de lo producido. Más aún, son transeúntes porque no terminan en sí mismas. En este marco, la noción de juego sólo podría circunscribirse al ámbito de las artes liberales, de las actividades que son praxis, que son fin en sí mismas y que guardan una íntima relación con la actividad ludente "que transcurre dentro de sí misma y se practica en razón de la satisfacción que produce su misma práctica". ${ }^{44}$ Por eso, el juego entendido como la actividad cerrada al mundo de los objetivos, absuelta del tiempo laboral y del espacio de la utilidad, emancipada de la vida corriente u ordinaria, sólo podrían realizarla indefinidamente los hombres libres, los no sujetos a la experiencia seria de la existencia, los que no tienen distancia que recorrer porque ya han llegado a la meta o al fin, también los que disfrutan de un ilimitado tiempo de ocio: los adultos que poseen patrimonio y los nińos. Lo declara Huizinga afirmando que "jugar no es ningún hacer o practicar", 45 "Todo juego es, antes que nada, una actividad libre. El juego por mandato no es juego"; ${ }^{46}$ también Callois sentenciando que "Sólo se juega si se quiere, cuando se quiere y el tiempo que se quiere. En ese sentido, el juego es una actividad libre". ${ }^{47}$ La satisfacción, el placer, o mejor, la felicidad propia de las acciones lúdicas es la correspondiente a aquellas cuyo fin permanece en el agente que actúa, por eso reciben el nombre de acciones inmanentes. Esa inmanencia también la constata Gadamer, permitiéndole defender que en el juego no hay propiamente objetivos. No obstante, como ha advertido González Valerio, "esto no quiere decir que se juegue para nada, sino que los objetivos del juego se cumplen sólo en el interior del juego. De este modo, la finalidad del juego se realiza en el juego mismo, hacien-

43. Ordine, La utilidad de lo inútil, 47.

44. Huizinga, Homo ludens, 22.

45. Huizinga, Homo ludens, 57.

46. Huizinga, Homo ludens, 20.

47. Caillois, Los juegos y los hombres. La máscara y el vértigo, 34. 
do que éste se autoconsuma sin necesitar de un fin exterior que lo valide en tanto medio". ${ }^{8}$

La seriedad está vinculada a lo útil, como lo lúdico está asociado a lo inútil pues no se ordena a ningún fin extrínseco. Las acciones libres, nobles y ociosas, las lúdicas e inmanentes, las que son praxis, son las propias del reposo porque la noción de juego y de ocio está emparentada con la conquista y posesión del fin, no en vano el ocio es el fin del movimiento que es el trabajo: neg-ocio. Platón anota en La República que "el espíritu libre no debe aprender nada como esclavo". ${ }^{49}$ Respecto de todo lo dicho - y con vistas a tener una visión "clásica" del juego y del ocio- es bien ilustrativa la sentencia aristotélica que leemos en Politica:

la naturaleza misma busca no sólo el trabajar correctamente, sino también la capacidad de gozar bien del ocio. Éste es, por repetirlo una vez más, el fundamento de todo. ${ }^{50}$

Pero el disponer de ocio parece ser la base misma del placer, de la felicidad y la vida dichosa. Ésta no está al alcance de los ocupados en trabajos, sino de los que disfrutan de tiempo libre; ya que el que está ocupado se afana con vistas a algo como un fin que posee, mientras que la felicidad es un fin que todos piensan que existe, acompañado, no de dolor, sino de placer. Sin embargo, ya no coinciden en establecer la identidad del placer, sino que cada uno lo define a su medida y según su propio carácter, aunque el hombre mejor elige el placer mejor y de mejores causas. ${ }^{\text {II }}$

La noción aristotélica de juego es tan aristocrática como su noción de trabajo. Para el estagirita la actividad lúdica estaría relacionada con la versión liberal de las artes y con la posesión de un tiempo de ocio, que se colma jugando. Como ha recordado Mary Beard, el juego, junto a la caza, el baño y la risa, era uno de los placeres dominantes para los miembros de la élite cultural y económica romana. ${ }^{52}$

Cabe, en su defecto, una versión del juego vinculada al descanso y a la distracción de los que se dedican a las artes serviles y que no gozan propiamente de otium porque no son dueños de su tiempo, tal es su servidumbre. En esta

48. María Antonia González Valerio, El arte develado. Consideraciones estéticas sobre la hermenéutica de Gadamer (México: Herder, 2005), 36.

49. Platón, La República, VII, 536d-e, 242.

50. Aristóteles, Política, VIII, 3, I337b, 308.

5I. Aristóteles, Politica, VIII, 3, I338a, 309.

52. Beard, SPQR. Una historia de la antigua Roma, 493. 
segunda versión, el divertimento lúdico tiene el carácter terapéutico de la pausa entre los tiempos de actividades productivas y fatigosas que son poiesis y en ese sentido, anota Caillois que: "Por el camino del juego, el hombre está en posibilidad de derrotar la monotonía, el determinismo, la ceguera y la brutalidad de la naturaleza"s3 y en la misma línea sentencia Huizinga que "así es, por lo menos, como se nos presenta el juego en primera instancia: como intermezzo en la vida cotidiana, como ocupación en tiempo de recreo y para recreo", 54 también el aquinate vincula las acciones lúdicas al agrado y a la proporción de descanso. 55 Esta noción de pausa no es propiamente la que se sigue de la noción de ocio sino la de "medida curativa" o "fuerza renovadora" dice Fink, la de ungüento reparador de las fuerzas vitales entre los tiempos de fatiga productiva, con el fin de diluir lo que Platón denomina "el embotamiento de las ocupaciones de la vida”. Por eso dice Aristóteles que:

hay que aprovechar los juegos en los trabajos (ya que el trabajo fatigoso necesita del descanso, y el juego aprovecha al descanso, mientras que el trabajo se hace con fatiga y esfuerzo), por eso hay que introducir juegos velando por su aplicación oportuna, aportándolos a modo de remedio medicinal. Ya que el movimiento anímico que producen es un relajamiento y por medio de su disfrute se logra un descanso. ${ }^{.6}$

Divertirse para obrar seriamente, como decía Anacarsis, parece que sea correcto - pues la diversión se parece al descanso, y, como no se puede trabajar continuamente, es menester un descanso. Pero, claro, el descanso no es un fin, pues se hace con vistas a la actividad. 57

Ciertamente, a nuestro modo de ver, una versión terapéutica de juego no sería más que un sustitutivo devaluado del auténtico sentido de lo lúdico. Aristóteles equipara el fin del juego con el placer reparador que éste conlleva como si fuese una actividad propiamente liberal o poiética.

Esta noción de juego como un intermezzo "se produce porque el placer de jugar, y de hacer de los juegos un fin, se confunde con el placer de ser feliz"; 58 más aún, esta marginal noción de juego, periférica respecto del paisaje vital de los

53. Caillois, Los juegos y los hombres. La máscara y el vértigo, 108.

54. Huizinga, Homo ludens, 22.

55. Aquino, Suma teológica (Madrid: BAC, 2009), I-II, q. I, a.6.

56. Aristóteles, Política, VIII, 3, I337b, 309.

57. Aristóteles, Ética a Nicómaco (Madrid: Alianza, 2007), X, 6, II76b, 300.

58. Yepes, La región de lo lúdico. Reflexión sobre el fin y la forma del juego, 34. 
hombres ${ }^{59}$ es la que se sigue de una visión del trabajo o actividad productiva como algo pobre y sórdido, diría Cicerón, propia de esclavos y siervos, poniendo de relieve que el humanismo clásico es eminentemente aristocrático. ${ }^{60} \mathrm{La}$ concepción del juego como intermezzo reparador de la vida cotidiana se acentuará con la segunda revolución industrial en el siglo xIX y durante el siglo Xx con la aparición del fenómeno "gente", ${ }^{61}$ de los fines de semana, de los espacios de consumo y de divertimento lúdico que seducen y fascinan diluyendo la fatiga de la vida cotidiana. Antes del siglo xx, advierte Choza, ni había propiamente gente ni había fines de semana ni había propiamente dinero sobrante para gastar superfluamente en espacios de consumo y de juego. Una noción de juego como actividad segregada de la vida corriente y cotidiana, "suspendida"62 dice Huizinga, separada del curso habitual de la vida y de las ocupaciones y preocupaciones por la subsistencia, participaría de la tesis clásica, en virtud de la cual, el juego es inconmensurable respecto de las actividades que son producción y no acción. "El juego no es la vida corriente o la vida propiamente dicha", ${ }^{63}$ es una actividad desinteresada y absuelta respecto de las ocupaciones y satisfacciones vitales, meramente materiales por lo que el reino de la libertad, la irrealidad y lo extraordinario se hallaría al completo segregado del de la necesidad y lo ordinario, sin que haya intersección alguna: "permanece separado, cerrado y en principio sin repercusión importante en la solidez y en la continuidad de la vida colectiva e institucional". ${ }^{64}$ En la misma línea apunta Gadamer cuando afirma que "la verdadera esencia del juego consiste en liberarse de la tensión que domina el comportamiento cuando se oriente hacia objetivos". 65

59. Las expresiones "marginal" y "paisaje vital" las tomo prestadas de Eugen Fink, El oasis de la felicidad. Pensamientos para una ontología del juego, trad. Elsa Cecilia Frost, Cuaderno, núm. 23 (Ciudad de México: Centro de Estudios Filosóficos, I966), II.

6o. Al respecto es bien reveladora la etimología de trabajo que procede del vocablo latino tripalium a saber: los tres palos del instrumento de tortura al que se ataba a siervos y esclavos para azotarlos. Jacinto Choza, Filosofía del arte y la comunicación. Teoría del interfaz (Sevilla: Thémata, 2015), I6I.

6I. El término gente es utilizado por Jacinto Choza para referirse al inmenso grupo de personas que pueden disfrutar del ocio y del arte de manera inédita desde finales del siglo xix. Choza, Filosofía del arte y la comunicación. Teoría del interfaz, 206.

62. Huizinga, Homo ludens, 27.

63. Huizinga, Homo ludens, 2I.

64. Caillois, Los juegos y los hombres. La máscara y el vértigo, in6.

65. Hans-Georg Gadamer, Verdad y método I (Salamanca: Ediciones Sígueme, 1999), I5I. 


\section{Incompatibilidad del juego con la vida corriente}

Más arriba se ha insistido en que el juego, en sentido estricto, es un tipo de actividad emancipada de las necesidades de la vida cotidiana y que al carecer de finalidad extrínseca sólo puede llevarse a cabo al margen de las obligaciones laborales, cuando éstas se han cumplido, o entre unas y otras, tal es su fragmentación y tal es el sentido terapéutico de la actividad lúdica: recarga emocional, física y psíquica del desgaste del trabajo y de las actividades serviles de los que no participan de la condición de hombres libres. Estos últimos son, según se ha indicado, los que poseen y disfrutan de tiempo pleno, emancipado de la subsistencia, de las preocupaciones materiales y del instinto de conservación. El tiempo libre al que aquí nos referimos es el propio del saber, del arte, del juego, de la fiesta, el tiempo de las teorías, las contemplaciones y las celebraciones, el tiempo de lo sagrado, la despreocupación y el desinterés respecto del provecho material y que no discurre del mismo modo que el tiempo profano, vacío y medible, corriente u ordinario. Huizinga lo define en los siguientes términos:

El juego no es la vida "corriente" o la vida "propiamente dicha". Más bien consiste en escaparse de ella a una esfera temporera de actividad que posee su tendencia propia. ${ }^{66}$ "[...] el juego, en su aspecto formal, es una acción libre ejecutada "como si" y sentida como situada fuera de la vida corriente, pero que, a pesar de todo, puede absorber por completo al jugador, sin que haya en ella ningún interés material ni se obtenga en ella provecho alguno, que se ejecuta dentro de un determinado tiempo $\mathrm{y}$ un determinado espacio, que se desarrolla en un orden sometido a reglas y que da origen a asociaciones que propenden a rodearse de misterio o a disfrazarse para destacarse del mundo habitual. ${ }^{67}$

"[...] el juego es una acción u ocupación libre, que se desarrolla dentro de unos límites temporales y espaciales determinados, según reglas absolutamente obligatorias, aunque libremente aceptadas, acción que tiene su fin en sí misma y va acompañada de un sentimiento de tensión y alegría y de la conciencia de "ser de otro modo" que en la vida corriente. ${ }^{68}$

Sin embargo, cuando la idea de utilidad comparece con más fuerza, y eso es algo propio de la modernidad y de nuestra contemporaneidad, más se radica-

66. Huizinga, Homo ludens, 2I.

67. Huizinga, Homo ludens, 27.

68. Huizinga, Homo ludens, 45-46. 
liza la segregación del juego y del arte como absolutamente independientes del provecho cotidiano. Todo ello, paradójicamente, conlleva a una noción aún más devaluada y pobre del juego y del arte, ${ }^{69}$ por lo que la unidimensionalidad del progreso, del mercado y de la productividad, del crecimiento material indefinido "no puede por menos que tratar de reducir el área de dichas actividades, que suponen un escarnio para el trabajo, tachándolas ideológicamente de inmorales y asociales". ${ }^{70}$

La actividad lúdica se tiene como opuesta al discurrir cotidiano y como mucho, anota Roger Caillois, discurrirá equidistante a la vida corriente: "actividad paralela, independiente, que se opone a los gestos y a las decisiones de la vida ordinaria por caracteres específicos que le son propios". ${ }^{71}$ En el espacio y el tiempo cotidiano se dan reglas y normas incompatibles con las que aparecen en el espacio y el tiempo lúdicos, poniendo de relieve la indiscernibilidad entre ambas esferas de la vida humana. Caillois define el juego como actividad "libre", "separada", "incierta", "improductiva", "reglamentada" y "ficticia".72 Coincide con Huizinga en la corrupción que supondría para el juego su vinculación contaminante y contagiosa con la realidad, ${ }^{73}$ con la producción, el interés, la necesidad, la utilidad y el provecho. La necesidad de delimitación espacial y temporal, como si de un recinto sagrado (témenos) o de un tiempo extraordinario se tratase, pretende evitar la intromisión de la realidad en la irrealidad del juego que degradaría los principios de la actividad lúdica, propia de los hombres libres o de los siervos que actúan en libertad sin más finalidad que la de jugar. Por eso, Caillois sentencia que los principios del juego se: "oponen fuertemente $[\ldots]$ al mundo de la realidad [...] subrayando que el juego es en esencia una actividad aparte", donde "toda contaminación con la vida corriente amenaza con corromper y arruinar su propia naturaleza". ${ }^{74}$ Más todavía, sostiene que el juego se desviaría funestamente al entrar en contacto con la vida ordinaria, "cuando el instinto que rige el juego se despliega fuera de los límites estrictos de tiempo y de lugar, sin convenciones previas e imperiosas". ${ }^{75}$

69. Carlos Morillas, "Huizinga-Caillois: variaciones sobre una visión antropológica del juego", Enrahonar, núm. I6 (1990): 22.

70. Morillas, "Huizinga-Caillois: variaciones sobre una visión antropológica del juego", 32.

7I. Caillois, Los juegos y los hombres. La máscara y el vértigo, I34.

72. Caillois, Los juegos y los hombres. La máscara y el vértigo, 37-38.

73. Caillois, Los juegos y los hombres. La máscara y el vértigo, 89.

74. Caillois, Los juegos y los hombres. La máscara y el vértigo, 87.

75. Caillois, Los juegos y los hombres. La máscara y el vértigo, 97. 
Fink también piensa la actividad lúdica como lo otro que la actividad cotidiana sujeta al carácter instrumental de medios y fines. Entiende el juego como una actividad segregada de la vida corriente, tal es el sentido del término "oasis" que da título a su obra. El oasis es un espacio distinto donde se lleva a cabo un tipo de actividad orientada a sí misma, como de hecho sucede en la diferenciación que Eliade ofrece entre lo homogéneo y lo heterogéneo, entre lo profano y lo sagrado. ${ }^{76} \mathrm{El}$ oasis es el espacio témenos, el de la heterogeneidad, en suma, el de la actividad radicalmente otra donde el tiempo se percibe como lo tranquilo, puro presente, pues no es la medida del espacio a recorrer hacia un fin aún no poseído. En ese "oasis" se está, siendo, plenamente. En el espacio lúdico, anota Fink, "El juego nos rapta. Al jugar nos liberamos, por un momento, del engranaje vital —estamos como trasladados a otro planeta donde la vida parece más fácil, más ligera, más feliz". .7

Tan incompatibles con la vida cotidiana son el juego como las artes, si por éstas entendemos la versión autónoma y absoluta que las caracterizarán desde el siglo XIx. Una referencia a la vida cotidiana, esto es, a un fin extrínseco al propio objeto artístico aumentaría lo que Rubert de Ventós ha definido como las alienaciones del arte, ${ }^{78}$ algo sensiblemente incompatible con su sentido desinteresado, con su voluntad de autonomía, también con las nociones de ocio y reposo a las que nos hemos referido más arriba, propias de la aristocracia liberal y de las élites sociales y culturales.

Para el autor de El arte ensimismado las alienaciones del arte son tres: figurativa, simbólica y decorativa. Cada una de ellas produce un extrañamiento del arte respecto de sí mismo por cuanto su finalidad sería extrínseca a la actividad artística que quedaría reducida a mera actividad poiética, artesanal y técnica donde lo producido tendría el carácter de medio, de instrumento que se puede repetir y puede sustituirse por otro en la función para la que está pensado. ${ }^{79} \mathrm{La}$ alienación figurativa convertiría la obra de arte en intermediaria entre el hombre y el mundo, dado que su dimensión viática reduciría el arte a mera representación y reproducción de lo real. ${ }^{80}$ La finalidad de la obra figurativa recaería del lado de su ajuste a lo real y a la naturaleza, pero no en la obra mis-

76. Eliade, Lo profano y lo sagrado, 2I.

77. Fink, El oasis de la felicidad, I4.

78. Xavier Rubert de Ventós, El arte ensimismado (Barcelona: Anagrama, 1997), 33-42.

79. Gadamer, La actualidad de lo bello, 92.

80. Rubert de Ventós, El arte ensimismado, 35-36. 
ma, carente de finalidad propia. La alienación simbólica o subjetiva, ${ }^{8 \mathrm{I}}$ reduciría el arte a evocar emociones o sentimientos por lo que la obra también quedaría desprovista de valor per se. Finalmente, la alienación decorativa ${ }^{82}$ se produciría cuando la finalidad del objeto artístico consistiera en su adecuación o encaje a su entorno, por lo que el arte también perdería autonomía quedando su legitimación subordinada a su integración ornamental. La alienación figurativa referida a lo figurado, la simbólica remitida a lo evocado y la decorativa supeditada al entorno serían las formas que corromperían la obra artística, "los enemigos de la pura alma abstracta", ${ }^{83}$ por cuanto su valor y su jurisdicción quedarían diferidos y subordinados a un momento segundo, el de su adecuación a un fin, que acabaría transformando la obra de arte en mero artículo productivo, repetitivo y sustitutivo.

La constatación, en el ámbito de las artes, de que todo aquello que tiene por finalidad la producción o la adecuación a un fin exterior, y de que todo lo que es un hacer con vistas a algo, y que no es propiamente el hacer mismo, queda alienado respecto de sí, dará lugar al agotamiento de la forma tradicional de producir y de gozar del arte hasta el siglo XIX. La autorreferencialidad del arte moderno, transformado en una suerte de praxis inmanente, pretendería la conquista de una inédita forma artística caracterizada por su absolutización, como si de una actividad lúdica o temporera se tratara, o de una actividad liberal propiamente contemplativa, desprovista de otra finalidad que la de su hacer mismo. Tal es el parentesco entre la noción de juego y de arte en su versión moderna y contemporánea.

\section{Ensimismamiento ${ }^{84}$ y autorreferencialidad de la actividad artística y lúdica}

Me he referido más arriba a la noción de juego y a su afinidad con las artes liberales al considerarlo completamente desvinculado de la vida corriente y cotidiana sujeta a la premura productiva, donde lo realizado es sustituible y reproducible. Una dimensión del juego y el arte vinculados a la ruda realidad, a la tensión de la vida cotidiana y al mundo de lo útil convertiría el juego y el arte en actividades instrumentales quedando, como se ha indicado, degrada-

8I. Rubert de Ventós, El arte ensimismado, 36-39.

82. Rubert de Ventós, El arte ensimismado, 40.

83. Rubert de Ventós, El arte ensimismado, 4I.

84. Rubert de Ventós, El arte ensimismado, 24. 
das, corrompidas y alienadas respecto de sí. Como ya se ha anotado, para evitar la instrumentalización alienante es necesario delimitar un espacio y un tiempo específicos, impidiendo que tanto el juego como el arte mantengan toda suerte de contacto con la vida productiva que los corrompería y los arruinaría transformándolos en medios para algo, pero no en fines en sí mismos.

La finalidad del juego es jugar y también, según ha sido defendido por Huizinga, Callois y Fink, proteger y reparar al sujeto mundano que, inmerso en el reino de la necesidad, alienado de su actividad y de sí, se comprime, deforma y embrutece su vida y su producción artística, como ha hecho ver el pragmático Shusterman: "Abandonado a deformarse debido a las presiones de la vida, que son en gran medida presiones deshumanizadoras del beneficio económico, crece robusto, técnicamente sofisticado pero brutalmente crudo en sensibilidad." ${ }_{5}$ Y en línea de afinidad con el juego, la finalidad del arte — sobre todo desde la modernidad y la segunda revolución industrial — también es el arte mismo, quedando desintegrado respecto de la comunidad y de la vida cotidiana, reducido su disfrute y consumo al tiempo de ocio que disfrutan las élites culturales y económicas.

Se ha constatado la familiaridad entre la actividad lúdica y las artes liberales, entre el juego y el arte ensimismado, completamente desinteresados respecto de un fin extrínseco que, a decir de Kant "estropea el juicio de gusto" ${ }^{86}$ Este desinterés ha permitido vincular la noción de juego con la de belleza que desarrollará en la Crítica del juicio (1790) y que posteriormente radicalizará Friedrich Schiller en las Cartas sobre la educación estética del hombre ${ }^{87}$ (I793-1795) donde sostiene que, mediante el arte, tal es su consanguinidad con la actividad lúdica, el hombre puede experimentar la existencia absoluta y temporera frente a la determinada por la mera realidad mundana y vital.

La referencia a Kant resulta inevitable puesto que define lo bello como lo en sí mismo valioso, lo incondicionado y que no puede ser objeto de conocimiento teórico dado que bello es lo que place sin concepto, sin contenido "pues el juicio de gusto no es un juicio de conocimiento (ni teórico ni práctico), y, por tanto, ni fundado en conceptos, ni tampoco dirigido hacia ellos". ${ }^{88}$ Si no puede ser objeto de conocimiento teórico, la belleza no puede ser una propiedad del objeto, por lo que Kant hará recaer la noción de belleza en el

85. Shusterman, Pragmatist Asthetics. Living Beauty, Rethinking Art, I68.

86. Inmanuel Kant, Crítica del juicio (Barcelona: Espasa, 20I4), I5O.

87. Schiller, Cartas sobre la educación estética del hombre.

88. Kant, Critica del juicio, 135 . 
sujeto que percibe. He ahí el giro copernicano aplicado al mundo de las artes: la belleza no es algo en el objeto sino en el sujeto.

No puede haber regla objetiva alguna de gusto que determine, por medio de conceptos, lo que sea bello, pues todo juicio emanado de aquella fuente es estético, es decir, que su fundamento de determinación es el sentimiento del sujeto, y no un concepto del objeto. ${ }^{89}$

No hay otra conciencia posible más que la sensación del efecto, que consiste en el juego facilitado de ambas facultades del espíritu (la imaginación y el entendimiento), animadas por una concordancia recíproca..$^{\circ}$

Kant definirá lo bello apelando al desinterés, a la ausencia de fin, o mejor a la "finalidad sin fin" y al juego: "Así, pues, el juicio estético, así como el juicio de lo bello refiere la imaginación, en su libre juego, al entendimiento, para concordar con los conceptos de éste en general." ${ }^{1}$ Del mismo modo que la finalidad del juego es jugar, la del objeto artístico es la pura forma desvinculada de concepto alguno, tal es su emancipación y al cabo su absolutización y ensimismamiento. El planteamiento kantiano dará lugar al esteticismo subjetivo, en cierto modo también al subjetivismo lúdico, radicalizándose las actividades artísticas y ludentes, tanto del contexto vital como de la realidad misma. Así es como emergerá la noción de bellas artes, dilatándose aún más la falla insalvable entre alta y baja cultura, entre arte elitista y arte popular; el primero emancipado de la vida cotidiana y productiva, y el segundo, sujeto a las necesidades mundanas de la gente corriente, en definitiva actualizando el dualismo clásico artes liberales (praxis)/artes serviles (poiesis).

Así las cosas, ni la experiencia artística ni la lúdica guardan propiamente relación con la vida corriente. En éstas comparece la necesidad, la productividad, el uso, el interés, los conceptos y los contenidos, también las tensiones y deformaciones de un sujeto que sólo se recompondrá fugándose al reino de la libertad completamente autónomo, emancipado, ensimismado y absoluto. ${ }^{92} \mathrm{El}$ arte y la belleza se absolutizarán como absoluto es el juego, quedando circunscritas a sus recintos específicos y a sus campos de juego, a los espacios del arte, los museos,

89. Kant, Critica del juicio, I6I.

90. Kant, Critica del juicio, 146.

91. Kant, Crítica del juicio, I89.

92. Desligado, opuesto a lo relacionado, independiente de cualquier limitación. Gadamer, Hermenéutica, estética e historia, 22I. 
los teatros, las galerías, los cenáculos artísticos y a las experiencias estéticas. Arte y juego sólo podrán disfrutarse en el ámbito de una vida elitistamente liberal, sin vínculo racional con la realidad, adentrándose en la irracionalidad e irrealidad que harán de la experiencia artística y lúdica una experiencia personal y subjetiva. En esas experiencias subjetivas será donde se lleve a cabo la referenciación absoluta y autónoma: "a ellos mismos y a nada más que a ellos", tal es su delimitación y ensimismamiento respecto de la vida cotidiana o de la realidad.

\section{Critica al arte y al juego ensimismados}

Kant emancipa el juicio estético del concepto, fundamentando la experiencia estética en las nociones de gusto, de genio y en el sentimiento privado de placer que produce el libre juego de la capacidad de conocimiento. Ni la belleza es concepto alguno de un objeto ni el juicio de gusto es un juicio de conocimiento ${ }^{93}$ de manera que, la conciencia estética acaba erigiéndose en la sede trascendental desde la que emitir el juicio sobre el arte dado que es la que distingue entre lo puramente estético y lo extra-estético: "Lo suyo es abstraer de todas las condiciones de acceso con las cuales se nos manifiesta una obra. [...] Distingue la calidad estética de una obra respecto a todos los momentos de contenido que nos determinan a tomar posiciones de contenido, morales o religiosas, y se refiere a la obra en su ser estético."94

$\mathrm{El}$ arte y el juego ensimismados — referidos a la experiencia sensible de la absoluta subjetividad trascendental — ajenos al reino de la necesidad y absueltos de cualquier finalidad extrínseca propia de la vida corriente, difícilmente pueden ser transmisores de conocimiento y verdad. Tal es su desinterés y su finalidad sin fin y, tal y como indica Gadamer, ésa es justamente la delicada y conflictiva situación en la que se ha situado el arte y, a nuestro juicio, también el juego. La propuesta que Gadamer lleva a cabo en La actualidad de lo bello y en Verdady método está orientada a la rehabilitación y renovación de la pregunta por el arte y el juego. Dicha propuesta, anota Zúńiga, se basará en una "lucha contra el método a favor de la verdad"95 aunque ésta no sea la verdad científica obsesio-

93. Kant, Critica del juicio, 230.

94. Gadamer, Verdady método I, 126.

95. José Francisco Zúńiga, "Arte y verdad: el límite de la estética de Gadamer”, en J. J. Acero, J. A. Nicolás, J. A. P. Tapias, L. Sáez, J. F. Zúñiga, eds., El legado de Gadamer (Granada: Universidad de Granada, 2004), i38. 
nada por la objetividad, pues el espacio de la obra de arte no es "el ámbito de la verdad de una proposición" ${ }^{96}$ El filósofo de Marburgo se alejará, como se ha indicado, de la abstracción y del subjetivismo trascendental que inaugurara Descartes - con el dominio universal de la noción de método capaz de certezas indubitables- y que consumara Kant desacreditando las posibilidades del conocimiento fuera de la metodología de las ciencias naturales, relegando las ciencias del espíritu a la disyuntiva "método o estética", produciéndose "la estetización de lo otro que el conocimiento de las ciencias exactas, asignándoles una esfera autónoma”. ${ }^{97}$ Como ha advertido González Valerio, Gadamer no comparte la teoría kantiana del arte por tres motivos. Primero, porque el subjetivismo reduce la experiencia artística a la del sujeto pues, en Kant, el juicio sobre lo bello sólo dice sobre el modo de representar del sujeto, sin afirmar nada del objeto. Segundo, porque la obra de arte tiene su propio sentido, y a pesar de ser interpretada por el espectador o por el jugador (en caso del juego), el sentido pertenece siempre a la obra de arte. Finalmente, si se admite, como anota González Valerio, que la totalidad de sentido recae solamente en el artista o en el jugador, nuevamente nos deslizaríamos hacia el subjetivismo, aunque no del espectador sino del artista. Ese subjetivismo conduciría a la noción de genio como el único sujeto capaz de sentido por lo que la obra de arte no sería más que expresión de su interioridad e individualidad cuando, para Gadamer, la obra de arte está relacionada con el sentido que funda la comunidad, esto es, con el sensus communis. $9^{8}$

Más aún, para Gadamer una fundamentación estética basada en el juicio de gusto puro - como si de una exclusiva vivencia subjetiva se tratara- y en el dominio de la conciencia estética que no conoce concepto alguno del objeto que se juzga y que considera cualquier orientación teleológica como una limitación o restricción, "es una teoría verdaderamente fatal para la comprensión del arte". ${ }^{99}$ Rafael Argullol ha descrito esta situación de manera muy reveladora en el prólogo a la obra de Gadamer La actualidad de lo bello constatando la paradoja que se produce entre la "perspectiva de la libertad que proporciona el subjetivismo y el estigma de orfandad en el que reconoce la ausencia de toda limitación objetiva". ${ }^{\circ 0}$

96. Gadamer, Hermenéutica, estética e historia, 239.

97. Óscar Lorca, "Arte, juego y fiesta en Gadamer", A parte Rei. Revista de Filosofía, núm. 4I (septiembre de 2005): 4 .

98. González Valerio, El arte develado, 52-53.

99. Gadamer, Verdad y método I, 78.

ıoo. Gadamer, La actualidad de lo bello, $\mathrm{I3}$. 
Para Gadamer, constata Zúñiga, la conciencia estética que se ha ido fraguando desde Kant y Schiller, cada vez más emancipada y autónoma conduce a un "arte puramente estético. Y esto significa: un modo de considerar el arte independientemente de su pretensión de verdad". ${ }^{\text {Ior }}$ El esteticismo que encierra la experiencia del arte en la exclusiva esfera del sujeto no debiera impedir que el arte pudiera ser transmisor de la experiencia de la verdad, de otro tipo de verdad que es posible comunicar y enunciar: la verdad de la obra de arte que "sale fuera", aunque no haya forma de decir qué es eso que sale, ni siquiera "cómo sale hacia fuera" ${ }^{102}$ Critica un modo de contemplación de la obra de arte "autónoma y libre del baremo del concepto" ${ }^{103}$ puramente estético, y reprueba, como se ha indicado, la soberanía irrestricta de la conciencia estética que elimina cualquier referencia a la generalidad, deshaciéndose de cualquier vínculo que pueda mermar la dimensión "autosignificativa"104 del arte. Duda de la eficacia y la idoneidad de las obras de arte abstractas, alejadas de su dimensión social y cognitiva; censura la separación entre arte y vida cotidiana, entre experiencia estética y contexto vital. En definitiva, cuestiona la capacidad del juicio estético kantiano que circunscribe en exclusiva "el concepto de gusto al ámbito en el que puede afirmar una validez autónoma e independiente en calidad de principio propio de la capacidad de juicio; y restringe a la inversa el concepto de conocimiento al uso teórico y práctico de la razón". ${ }^{\text {Ios }}$

La abstracción del arte y la reducción de la experiencia estética al ámbito de la conciencia trascendental dificultan la pretensión de verdad y de conocimiento que el arte conlleva. El autor de Verdad y método se pregunta, al criticar la abstracción de la conciencia estética: “`cómo se puede hacer justicia a la verdad de la experiencia estética y superar la subjetivación radical de lo estético que se inicia con la Crítica de la capacidad de juicio estética de Kant? [...] ¿o ha de haber, pues, en el arte conocimiento alguno? ¿No se da en la experiencia del arte una pretensión de verdad diferente de la de la ciencia pero seguramente no subordinada o inferior a ella?"

IoI. Zúñiga, "Arte y verdad: el límite de la estética de Gadamer”, I48.

IO2. Gadamer, Hermenéutica, estética e historia, 242.

I03. Gadamer, Verdad y método I, 95.

I04. Gadamer, Verdad y método I, I30.

I05. Gadamer, Verdad y método I, 73.

I06. Gadamer, Verdad y método I, I39. 
El arte, el artista y el espectador pierden su apoyo en la realidad, y al cabo "su lugar en el mundo", ${ }^{\text {I07 }}$ cuando fundamentan la experiencia del arte en una abstracción metodológica cuya finalidad explícita no es otra que la comprensión del arte en términos puramente estéticos, pero no racionales ni lógicos ni conceptuales, propios de las ciencias naturales. Constata que el primado de la subjetividad y su emancipación de la realidad segrega y desarraiga al artista de su mundo, lo desintegra de la sociedad y lo margina; libre de determinaciones, objetivos, funciones y significaciones ya no trabaja por encargo, tal es la desconexión respecto del mundo y la independencia de su creación que abstraída y absuelta de cualquier referencia a lo mundano y objetivo desprovee al artista de su comunidad: ésa es "la tragedia del artista en el mundo", su marginación y la explicación de espíritu de vida bohemia. ${ }^{\mathrm{I} 8} \mathrm{La}$ conciencia, la intencionalidad y la distinción estéticas sitúan al arte abstracto en una esfera completamente libre que sólo podrá ser representada en los espacios segregados y desprovistos de conexión con la realidad: galerías, museos, teatros, salas de exposiciones, bibliotecas, cenáculos de expertos, entre otros. Así es como el arte inicia su andadura selectiva y elitista que lo desconectará de lo mundano y popular, marginando al artista que ya sólo servirá al arte, dilatándose la discontinuidad entre lo culto y lo popular, entre lo liberal y lo servil, entre arte y comunidad. Distancia, escisión y desintegración inexistente en épocas pasadas, pues como anota Gadamer en algunos de sus escritos

el arte de entonces — se refiere al de la Antigüedad — que se justificaba en una unión última con todo el mundo de su entorno realizaba una integración evidente de la comunidad, la Iglesia y la sociedad, por un lado, y con la autocomprensión del artista creador, por otro. [...] En el siglo XIX, todo artista vivía en la conciencia de que la comunicación entre él y los hombres para los que creaba había dejado de ser algo evidente. ${ }^{109}$

En cualquier caso, no cabe duda de que las grandes épocas en la historia del arte fueron aquellas en las que la gente se rodeó, sin ninguna conciencia estética y sin nada parecido a nuestro concepto del arte, de configuraciones cuya función religiosa o profana en la vida, era comprensible para todos y que nadie disfrutaba de manera puramente estética. ${ }^{\text {IIO }}$

107. Gadamer, Verdad y método I, I28.

108. Gadamer, La actualidad de lo bello, 36 .

I09. Gadamer, La actualidad de lo bello, 36 .

IIO. Gadamer, Verdad y método I, I20. 
Tanto si pensamos en la Pasión de Bach, que en la iglesia congrega en una experiencia común a los amantes de la música sublime y a los verdaderos miembros de la comunidad cristiana, como si pensamos en el teatro griego, cuyos textos aún ofrecen un material inagotable a la cultura intelectual de generaciones y al ingenio de los doctos y que, sin embargo, cautivaban a todo el público teatral de Ática, desde artesanos a la crema de la sociedad. ${ }^{\mathrm{II}}$

En definitiva, para Gadamer una estética trascendental es la que se sigue de la circunscripción de las posibilidades de conocimiento al uso teórico y práctico de la razón, relegando el gusto al ámbito de la autonomía del sujeto, privando a las humanidades, también al arte, del carácter científico de su legitimación de verdad. Urge una renovación de la pregunta ¿Qué es arte? "preguntaremos a la experiencia del arte qué es ella en verdad y cuál es su verdad aunque ella no sepa lo que es y aunque no pueda decir lo que sabe". ${ }^{\text {II2 }}$ Más aún, si lo que se pretende es mantener en el arte la posibilidad de transmisión de la verdad hace falta revisar el carácter absoluto de la subjetividad y la conciencia estética, de manera que

Para reconocer qué significado fundamental posee la pregunta por la esencia de la obra de arte y de qué manera está en conexión con las preguntas fundamentales de la filosofía hay que reconocer, ciertamente, los prejuicios inherentes a la concepción de la estética filosófica. Es necesario superar el concepto mismo de estética. ${ }^{113}$

\section{Superación del subjetivismo: el juego como sujeto}

La revolución artística caracterizada por la desintegración y por su segregación respecto de la vida cotidiana precisa, a decir de Gadamer, una tarea y una renovación de la pregunta por el arte. Esa renovación pretende superar el subjetivismo esteticista que acabó segregando la creación artística de la mundanidad cotidiana, alienada respecto de sí, volviendo indiscernibles e inconmensurables el arte del genio y la vida corriente, impidiendo "el entretejimiento de arte

III. Hans-Georg Gadamer, La herencia de Europa (Barcelona: Península, 2000), 72.

II2. Gadamer, Verdad y método I, I42.

II3. Hans-Georg Gadamer, "La verdad de la obra de arte", en Los caminos de Heidegger (Barcelona: Herder, 2002), 99. 


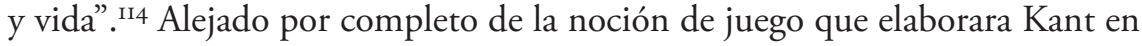
la Crítica del juicio mantiene en vigor un segmento de la ontología del juego defendida por Huizinga, en cuya virtud éste es autorreferencial, carece de utilidad productiva, es un fin en sí mismo, y se distancia tanto de la noción aristotélica que lo vinculaba con el descanso y el ocio como de la de Fink que lo segregaba de la realidad cotidiana. No obstante, confiere a la actividad lúdica un nuevo estatuto ontológico consistente en ser la manifestación, la puesta en escena y representación del automovimiento de la vida, fascinando a la conciencia ludente que sale de sí para sumergirse en la dinámica del juego. ${ }^{\text {II }}$ Más aún, constata el elemento lúdico del arte y transforma el juego en juego del arte por cuanto su automovilidad está emancipada de fin o meta alguna, quedando orientada "al movimiento en cuanto movimiento" ${ }^{116} \mathrm{Si}$ el juego deviene obra, anota González Valerio, alcanza su perfección pues se muestra al completo emancipado de los jugadores con lo que la determinación de sentido no depende en exclusiva de ellos ${ }^{117}$ como la que, de hecho, se derivaba del esteticismo kantiano. Esta autonomía del juego respecto de los jugadores y del arte respecto del artista y del espectador se lleva a cabo mediante la "transformación en una conformación". Dicha transformación, anota Gadamer, convierte el juego en una cosa diferente, situando a los jugadores, a los artistas y a los espectadores en una posición secundaria frente a la que ocupaban antes de la transformación en una conformación: "Nuestro giro transformación en una conformación quiere decir que lo que había antes ya no está ahora. Pero quiere decir también que lo que hay ahora, lo que se representa en el juego del arte, es lo permanentemente verdadero". ${ }^{\text {II8 }}$ De esta manera, Gadamer desplaza la subjetividad haciendo notar que la experiencia del juego y del arte consiste en un ser jugado y en un abandonarse a ambos lo que, no obstante, deja intacta la importancia del jugador, del artista y del espectador para hacer emerger el sentido: "el 'ello' que sale fuera y entra en el interior de uno". ${ }^{19}$ El primado del juego sobre el jugador se pone de manifiesto en el abandonarse de éste a aquél, de ahí que el sujeto de la actividad lúdica no sea el jugador sino el juego: "el verdadero sujeto del juego no es con total evidencia la subjetividad del

II4. Gadamer, Estética y hermenéutica (Madrid: Tecnos, 200I), I36.

II5. Hans-Georg Gadamer, Verdad y método II (Salamanca: Ediciones Sígueme, 2002), I50.

II6. Gadamer, La actualidad de lo bello, 67.

II7. González Valerio, El arte develado, 5 I.

II8. Gadamer, Verdad y método I, I55.

II9. Gadamer, Hermenéutica, estética e historia, 243. 
que, entre otras actividades, desempeña la de jugar (sino que) el sujeto es más bien el juego mismo". ${ }^{120}$ En este sentido, anota Daniel Orueta, "El análisis del fenómeno del juego sufre en Gadamer un desplazamiento de la importancia que el juego mismo adquiere al aceptarse que el jugador está completamente sometido a la estructuración que el juego impone". ${ }^{\text {I2I }}$

Ese abandonarse en el juego y el arte obliga a someterse libremente a sus reglas y normas, tal es la soberanía del juego sobre el jugador y tal es parte de la esencia del juego: "las reglas e instrucciones que prescriben el cumplimiento del espacio público constituyen la esencia del juego". ${ }^{122}$ No obstante, la aceptación de esas reglas no genera la sensación de falta de dominio en el jugador, más bien colma su espíritu de ligereza, libertad y felicidad. ${ }^{\mathrm{I} 23}$ Ése es el giro que presenta la tesis gadameriana, a saber: que la esencia del juego no se halla en la conciencia del jugador, ni la esencia del arte en la conciencia estética del sujeto, pues lo único que puede ser descrito desde la conciencia trascendental es el comportamiento del jugador o del sujeto, pero no el juego ni el arte. ${ }^{\mathrm{I} 4} \mathrm{El}$ jugador, el artista y el espectador estarían en una posición de sujeto sobre un objeto si juego y arte fueran productos de un hacer orientado a fines externos. Pero el juego y el arte no son producidos como mercancías pues el fin de aquéllos emerge en la propia acción, en acto, en su ejecución, lo que representa el modo ser óntico de la obra de arte y del juego, tal es la novedad.

En suma, la relación entre jugador y juego no es la de un sujeto con un objeto. Si fuese así, se caería en el esteticismo y en el subjetivismo intensamente censurado por Gadamer tanto en la estética del genio y del gusto kantianos, como en el subjetivismo hermenéutico de Schleiermacher que supeditaba la comprensión de los textos a su autor, ${ }^{125}$ como en el caso de Collingwood que hacía recaer el sentido de lo histórico en el agente. ${ }^{\mathrm{I} 26} \mathrm{Ni}$ el arte ni los textos ni la historia nos pertenecen, somos más bien nosotros los que le pertenecemos, tales son las limitaciones de nuestra comprensión. Gadamer es muy explícito y afirma que: "El juego no tiene su ser en la conciencia o en la conducta del

I20. Gadamer, Verdad y método I, I47.

I2I. Sebastián Daniel Orueta, "Gadamer: el arte entendido a través del juego", Scientia Helmántica. Revista Internacional de Filosofía, núm. 2 (noviembre, 20I3): 84.

I22. Gadamer, Verdad y método I, I5O.

I23. Gadamer, Verdad y método II, I5O.

I24. Carlos Marzán, "Sobre el concepto de juego en Gadamer", Laguna, Revista de Filosofía, núm. 6 (1999): 316.

125. Gadamer, Verdad y método I, 239, 243.

I26. Gadamer, Verdad y método I, 449. 
que juega, sino que por el contrario atrae a éste a su círculo y lo llena de su espíritu." 27

En este sentido, el juego adquiere un estatuto ontológico nuevo, dado que se convierte en el sujeto auténtico del movimiento lúdico. Eso no quiere decir que la presencia del jugador sea irrelevante e innecesaria. Más bien pone de relieve: primero, que el juego precisa que se juegue por un jugador; segundo, que "el jugador es la condición de posibilidad para que el juego alcance su representación"; ${ }^{128}$ tercero, que el juego y el arte son percibidos por el espectador, quien es considerado no tanto como algo separado ${ }^{\text {I29 }}$ de la representación del juego y del arte sino, más bien, como sustancial y como medio para hacer emerger su sentido, para hacer posible el salir afuera lo otro que la realidad cotidiana y medible.

\section{El juego y el modo de ser de la obra de arte: presencia y representación}

Como ya se ha insistido, Gadamer pretende superar la tensión sujeto-objeto criticando la idea de que la verdad del arte sea propiedad exclusiva de la subjetividad. Se aleja del proceso de subjetivación total de la realidad que se iniciara con el cogito cartesiano y su dogmatismo autoconsciente, se desarrollara con el sapere aude kantiano y se radicalizara con el mandato "compórtate estéticamente" que Schiller propusiera transformando la idea trascendental de gusto del filósofo de Königsberg.

El autor de Verdad y método insiste, tal y como ya he referido, que "el ser del arte no puede determinarse como objeto de una conciencia estética [...]. Es parte del proceso óntico de la representación y pertenece esencialmente al juego como tal". ${ }^{130}$ Vincula el juego a la experiencia estética y sentencia que el juego es "el modo de ser de la propia obra de arte". ${ }^{131}$ Arte y juego están emparentados por cuanto uno y otro son los auténticos sujetos de la actividad artística y lúdica hasta el punto, más abajo se verá, que la existencia del arte y del juego no precisa propiamente la existencia de sujetos artísticos o ludentes.

I27. Gadamer, Verdad y método I, I53.

I28. Orueta, "Gadamer: el arte entendido a través del juego", 85.

I29. González Valerio, El arte develado, 47.

I30. Gadamer, Verdad y método I, I6I.

I3I. Gadamer, Verdady método I, I43. 
Ni el juego ni la obra de arte pueden considerarse como meros datos objetivos elaborados desde una conciencia subjetiva, por lo que un planteamiento de lo lúdico y lo estético, desde la noción de acontecer y no desde el conocimiento, se adecua más a dichas realidades.

Si el juego y el arte son independientes de la conciencia del sujeto entonces el sujeto de la experiencia artística y lúdica

no es la subjetividad del que experimenta sino la obra de arte misma: $Y$ éste es precisamente el punto en el que se vuelve significativo el modo de ser del juego. Pues éste posee una esencia propia, independiente de la conciencia de los que juegan. También hay juego, e incluso sólo lo hay verdaderamente, cuando ningún "ser para sî" de la subjetividad limita el horizonte temático y cuando no hay sujetos que se comporten lúdicamente. ${ }^{32}$

Del mismo modo que juego y arte comparten ser en esencia a los verdaderos sujetos, en ambos tampoco cabe hacer una distinción entre forma y representación. Tal distinción es imposible puesto que solamente por medio de la representación se puede acceder al "verdadero ser" del arte y del juego. De manera que ni el juicio lúdico ni el juicio estético pueden realizarse fuera de su escenificación, pues su ser es correlativo a su representación. Eso no quiere decir que juego y arte carezcan de significación propia. Pone de relieve, más bien, que es en su manifestación representativa cuando alcanzan su perfección; que, como anota Daniel Orueta, el juego y el arte son una presencia que es representación y ésa es, a decir de Gadamer, propiamente su esencia:

Hemos partido de que la obra de arte es juego, esto es, que su verdadero ser no se puede separar de su representación y que es en ésta donde emerge la unidad y mismidad de una construcción. Está en su esencia el que se encuentra referida a su propia representación. ${ }^{33}$

Hay arte si se representa y hay juego si se representa. Por eso se ha afirmado que el modo propio de ser de la obra de arte es el juego, que su ser se muestra en la representación, que se representa como juego: "En el jugar el juego se hace presente". ${ }^{134}$

132. Gadamer, Verdad y método I, I45.

I33. Gadamer, Verdad y método I, 167.

I34. Orueta, "Gadamer: el arte entendido a través del juego", 89. 
¿Qué es lo representado? Lo verdadero ${ }^{135}$ del arte y del juego. No obstante, cabe pensar que lo representado, es decir, lo verdadero, no es definitivo, pero genera un "incremento de ser" ${ }^{136}$ pues, una de las características del juego es su carácter inconcluso, no definitivo, en cuanto a su perfección y a su representación. Lo representado no es algo petrificado sino, más bien, algo dinámico y en proceso, en transformación. El juego y el arte son realidades abiertas. Aunque exigen su representación, cada una de ellas es nueva, como nueva es cada interpretación musical y nueva es cada partida de ajedrez, pero no son definitivas porque "está en la esencia de la emanación que lo emanado sea un exceso" ${ }^{137}$ de modo que sería incomprensible desde la finitud de lo humano pensar en la idea de una única y definitiva representación del arte y del juego. La interpretación definitiva, auténtica y canónica, no es posible en el ámbito de la finitud humana. ${ }^{138}$

\section{Conclusión: la retórica del juego y el arte}

Juego y arte son los verdaderos sujetos de una actividad que sólo puede activar el jugador y el artista. Mediante dicha acción se hace presente la verdad de lo real. Dicho de otro modo, el poner en obra del arte y del juego sólo acontece como verdad en la acción humana, que no es propiamente el sujeto del acontecer del juego y del arte sino el medio a través del cual la verdad de lo real se abre paso. Verdad que en el contexto de la hermenéutica de Gadamer no es definitiva, pues cada vez que se representa lo hace como "incremento de ser", tal es su dinamismo, su apertura y su carácter procesual.

Las acciones libres realizadas — en el marco de las reglas de juego de cada actividad - con perfección, inventiva y genio, sirven para romper el fijismo de una realidad inalterable y acabada que con dificultad tolera la libertad de interpretación. La novedad de la invención, del genio y del buen gusto no suponen ocultamiento ni trasgresión de la normatividad de cada actividad o de cada juego, en este sentido no son "aguafiestas". Más bien cancelan la idea de una ratio normativa incapaz de asumir la novedad de la libertad y que bien recuerda a la diferencia entre el artesano, perito en la aplicación de normas y reglas que le vienen dadas sin posibilidad de mejoría y de innovación, y

135. Gadamer, Verdad y método I, I55.

136. Gadamer, Verdad y método I, I89.

137. Gadamer, Verdad y método I, 189 .

138. Gadamer, La actualidad de lo bello, 50. 
la del artista que - aun sometido a las reglas y las normas que regulan la actividad - consigue mediante su ingenium y su genius, su talento y su genio expresar la apertura dinámica de lo real que se hace visible a través de la perfección del obrar libre: "lo asombroso del impulso artístico no es precisamente su carácter impulsivo sino el aliento de libertad inherente a sus formaciones". ${ }^{339}$ Más aún, la diferencia entre el artesano y el artista sería la diferencia entre no estar en sus obras (ése sería el sentido del trabajo gremial que impedía que las obras tuvieran propiamente autor) y estarlo plenamente, como hace el artista, pudiendo firmar las obras que realiza con destreza e ingenio: "La corporalización de la libertad es el arte", "I40 anota Zúñiga.

La expresión "el sujeto del juego no es el jugador sino el juego mismo", tiene el mismo sentido que la idea, también de Gadamer, de que quien habla en las conversaciones, además de los interlocutores, es el lenguaje mismo. El lenguaje mismo tiene sus propias leyes fonéticas, por las cuales unas cosas no suenan bien y otras sí, y leyes sintácticas, por las cuales unas construcciones o unas expresiones son más claras que otras o más bellas que otras. Los poetas son los que renuevan el lenguaje descubriendo nuevas formas de decir que permiten que el lenguaje llegue más lejos y diga más. Eso pasa también con el arte y con el juego. Hay jugadores y artistas que innovan (en la pintura, en la poesía, en la música, en el fútbol, en el tenis, en los juegos) y llevan esas actividades artísticas, esos deportes y esos juegos más allá de donde estaban. No obstante, eso no es sólo obra de esas personas singulares, sino también de esas actividades artísticas, esos deportes y esos juegos. Al respecto anota Choza que:

Cuando Cruyff decía que el fútbol se renueva en las playas de Río de Janeiro y no en las escuelas de fútbol, quería decir que la gente de las playas de Río tienen creatividad y genio, pero que también lo que ellos hacen es jugar al fútbol y no a otra cosa, ellos ejercen su talento en un sistema de normas que ofrece esas posibilidades nuevas que ellos inventan. También el hormigón y la fibra de carbono permiten innovaciones que no destruyen las normas del juego de los elementos en arquitectura, sino que permiten llevar ese juego y esas normas hasta alcanzar figuras nunca antes alcanzadas. ${ }^{{ }^{141}}$

Esa actividad activante propia del artista y del jugador no necesariamente es la que se lleva a cabo en los tiempos de ocio, ni es necesariamente el fruto de

139. Gadamer, Estética y hermenéutica, I3I.

I40. Zúñiga, "Arte y verdad: el límite de la estética de Gadamer", I40.

I4I. Debo esta idea al profesor Jacinto Choza, catedrático de Antropología Filosófica en la Universidad de Sevilla, en comunicación personal. 
la mera contemplación, ni siquiera es mera comprensión teórica al modo de la praxis. Más bien, y de manera más corriente, se lleva a cabo en el ámbito de todas las actividades cotidianas, las que hemos referido como poiéticas, pues todas pueden ser ocasión de desvelamiento, representación y puesta en escena de lo verdaderamente real cuando se realizan con perfección inventiva y con ingenio. Anota Gadamer que

¿No es, siempre, entonces, una falsa apariencia separar juego y seriedad, consentir el juego sólo en ámbitos limitados, en zonas al margen de nuestra seriedad, en el tiempo libre que, como un vestigio, testifica nuestra libertad perdida? En verdad, juego y seriedad, el movimiento vital de exceso y exaltación y la fuerza tensa de nuestra energía vital, están entretejidos en lo más profundo. Cada uno repercute en otro. ${ }^{142}$

En todas las acciones cabe la posibilidad de ese momento decisivo de la innovación artística, donde lo importante no es el hacer sino el hacerlo de una forma peculiar, muy singular e imprevisible, única e irrepetible que da lugar a la conformación ${ }^{\mathrm{I} 33}$ — construcción— ${ }^{\mathrm{I} 44}$ que cabe "reconocer" con asombro. Artista no es sólo el que lleva a cabo actividades extraordinarias, ni el que lleva a cabo acciones - en el sentido liberal del término que hiciera fortuna desde Aristóteles hasta finales del siglo XVII- ${ }^{\mathrm{I}} 45$ también es quien en el seno de la vida corriente y mundana, penetrando en "todos los órdenes de nuestra vida social, a través de todas las clases, las razas y los niveles culturales" ${ }^{146}$ lleva a cabo un hacer que no es mera producción repetitiva, mecánica, sin plusvalía antropológica. El deletrear no es el leer y el decir no es un mero hablar, y el hacer no es un mero producir sino un hacer visible - mediante la actividad comprensiva- la verdad de lo real, lo "verdaderamente permanente", que no es lo fosilizado sino lo que, al ponerse en escena, da lugar a un incremento de ser, tal es su sentido retórico. El juego y el arte lo son propiamente cuando ofrecen la posibilidad de mejoría, de exceso sobre lo dado porque, como anota Gadamer: "está en la esencia de la emanación el que lo emanado sea un exceso". ${ }^{147}$ \$

142. Gadamer, Estética y hermenéutica, 136.

143. Gadamer, Estética y hermenéutica, 132.

I44. Gadamer, Verdad y método I, 156.

145. Shiner, La invención del arte. Una historia cultural, 57-94.

146. Gadamer, Estética y hermenéutica, 137.

147. Gadamer, Verdad y método I, I89. 